\title{
Rheumatology training in Poland vs. United Kingdom
}

\author{
Karina Lazarewicz ${ }^{1}$, Hector Chinoy ${ }^{1,2}$ \\ ${ }^{1}$ Rheumatology Department, Manchester Academic Health Science Centre, Salford Royal NHS Foundation Trust, Salford, \\ United Kingdom \\ ${ }^{2}$ The National Institute for Health Research Manchester Musculoskeletal Biomedical Research Unit, Central Manchester University \\ Hospitals NHS Foundation Trust, The University of Manchester, Manchester, United Kingdom
}

\begin{abstract}
When evaluating the quality of Rheumatology specialty training, it can be useful to explore similarities and differences between countries. In this article we compare the training in the UK and Poland. The two training programmes are similar in length and in the competencies that must be achieved, although they do have significant differences in the way the training is structured. The UK-based system is more out-patient based, which can be advantageous, as after completion of training the doctor is more confident in treating common rheumatological problems.

On the other hand, having exposure to paediatric rheumatology and orthopaedics like one has in Polish-based training, despite a short placement time, is definitely beneficial for the trainee in gaining all-round knowledge.

In conclusion, each system has its merits and can be further enhanced by observing how junior doctors are sub-speciality trained in different countries.
\end{abstract}

Key words: education, rheumatology training, United Kingdom vs. Poland.

\section{Introduction}

When evaluating the quality of Rheumatology specialty training, it can be useful to explore similarities and differences between countries. Rheumatology specialists' education systems vary between European countries due to differences in the structure of health care organizations. Total unification of specialist education is probably not possible, but convergence of the specialization would be beneficial for scientific cooperation and improved patient treatment outcome. In Europe many doctors choose to practise medicine in a different country than the one in which they graduated from medical school. Therefore it would be definitely beneficial to the young doctors if the training in the speciality of their choice was similar throughout the globe. One of the authors, Dr Lazarewicz, has had the benefit of practising medicine in both the UK and Poland. Therefore we chose those countries for more in-depth analysis of similarities and differences in Rheumatology training. In both countries doctors can practise Rheumatology as a single specialty (single accreditation) or together with general medicine (dual accreditation). In recent years more and more UK citizens have been opting to study medicine abroad. In Poland there is a dedicated English-taught course for those who come from different countries and wish to commit to a six-year long medical degree course.

\section{United Kingdom: foundation and core medical training}

After medical graduation, UK trainees interested in general internal medicine must attend a 2-year Foundation programme and then apply for either "Core Medical Training" or the "Acute Care Common Stem". These comprise a two-year rotation through different medical specialties. Each rotation is usually four or 6 months long and doctors are usually expected to change hospitals each year. Trainees must also pass a postgraduate medical exam, the Membership of the Royal College of Physi- 
cians (MRCP UK), comprising three parts - two multiple choice questions and a practical exam, the "Practical Assessment of Clinical Examination Skills". Failure to pass the MRCP means that a trainee would not be allowed to apply for further (higher) specialty training such as in Rheumatology.

In general this is a very well-structured programme, but the downside is that the trainee might not be given the opportunity to experience the specialty they are interested in pursuing in the future.

\section{United Kingdom: specialty application process}

The application for UK Rheumatology sub-specialty training consists of a long structured on-line application that aims to assess all aspects of professional development, including leadership and management, teaching, courses attended, commitment to specialty and achievements outside of medicine. The application also includes personal data, eligibility, fitness to practise, references, employment record as well as competencies. After being shortlisted, one is invited to attend a structured interview. During the interview there are usually three stations: i) review of relevant documentation, commitment to the specialty, and achievements to date; ii) clinical scenario and communication station; iii) ethical scenario and discussion on professionalism and governance [1].

\section{United Kingdom: higher specialty training}

When successful candidates are appointed to commence UK Rheumatology training, they commit to five years of rotation through different hospitals (four years if they are only singly accredited). After completion of training, a successful doctor can be dually accredited in both Internal Medicine and Rheumatology. During those five years of training one must pass the Specialty Certificate Examination (SCE) that can be attempted during the training [2], usually during the final years. This is definitely a great solution, as being able to take the SCE during the training reduces the stress and pressure that trainees face at the end of training when looking for a new consultant job.

\section{Poland: internship and general medical training}

In Poland, after graduation from medical school, one goes straight into an internship year. After successfully completing the Medical Final Examination (Lekarski Egzamin Końcowy), trainees apply for General Medical Training of five years duration.
In 2014 the specialty programme became module-based for newly qualified doctors. Previously, after successfully finishing the five-year course and passing the General Medical National Specialty Exam, trainees were able to apply further for sub-specialty training, e.g. Rheumatology (this applies to those who started specialty training before 2014). Successful inclusion in sub-specialty training depends on exam grade and number of places allocated to the specific training specialty in the chosen region. Sub-specialty training lasts a further three years, usually based on one ward, with only short placements on other wards, and ending with the National Specialty exit exam (Państwowy Egzamin Specjalizacyjny). In contrast to the UK training, in Poland trainees may have more limited exposure to out-patient clinics [3]. If a doctor has to take only one written knowledge exam as a way to get into a desired training programme, it assesses only on one aspect of being a good doctor. It does not take into consideration all the other important elements such as team work, working under pressure, professionalism or leadership skills.

As part of the new module-based specialty training, Polish trainees start with the basic general medical module of 70 weeks (350 days) duration, based at a chosen ward in one hospital. In addition there are several placements of a few weeks duration in different specialities, e.g. cardiology, respiratory medicine or ITU (Table I) - bringing the total to three years. The curriculum has a number of competencies to be met prior to finishing the specialty programme. Those are similar to the ones in the UK curriculum. However, the main difference is that there is no uniform way by which they are assessed apart from the exam with the training leader, usually only one doctor. In summary, the module in Poland is 3 years long, finishing with an exam with the training director. Upon successfully finishing the Polish general medical module, a two-year long Rheumatology module can be commenced. It consists of 3-day long introductory course, immunology course, radiology course and a few courses that the doctor can choose. This is then followed by 62 weeks of general rheumatology in a chosen hospital, and in addition, 6 weeks of paediatric rheumatology, and one week each of radiology, orthopaedics, neurology, rehabilitation medicine, dermatology, and pain medicine. There then follows a 4-week placement chosen by the programme director and a six-week out-patient placement (Table II). The Rheumatology state exam comprises the final assessment [4]. By contrast, in the UK, trainees must change hospitals every year to gain an all-round experience of working in both larger university hospitals and in smaller district general hospitals.

Having short placements on many wards could be beneficial as the trainee has the opportunity to experi- 
Table I. Basic GIM training - 3 year's duration. Table translated from CMPK website (Centre of Postgraduate Medical Education: http://www.cmkp.edu.pl/ksztalcenie-podyplomowe/studia-specjalizacyjne-lekarzy/ programy-specjalizacji-lekarskich/modulowe-programy-specjalizacji/)

\begin{tabular}{|c|c|c|}
\hline No. & Training & Duration in weeks \\
\hline 1 & Basic GIM training & 70 \\
\hline 2 & ITU placement & 4 \\
\hline 3 & Cardiology & 16 \\
\hline 4 & Respiratory medicine & 6 \\
\hline 5 & Gastroenterology & 6 \\
\hline 6 & Endocrinology & 6 \\
\hline 7 & Nephrology & 3 \\
\hline 8 & Haematology & 3 \\
\hline 9 & Rheumatology & 3 \\
\hline 10 & Infectious Diseases & 3 \\
\hline 11 & Neurology & 3 \\
\hline 12 & Psychiatry & 2 \\
\hline 13 & Speciality courses & 7 weeks and 1 day \\
\hline 14 & Study leave & 1 \\
\hline 15 & Annual leave & 7 weeks and 4 days \\
\hline 16 & Total & 156 weeks and 3 days \\
\hline
\end{tabular}

ence the specialty, but it could be very superficial and potentially might not be sufficient to gain basic skills in the subject. In contrast, for example, as far as rheumatology training is concerned, UK trainees are only placed on rheumatology wards; there is no extra time in the curriculum specifically devoted to orthopaedic or paediatric clinics. However, depending on the hospital, some trainees will be attending combined or subspecialty clinics that could include paediatric, orthopaedic or dermatology clinics.

\section{United Kingdom vs. Poland - out-patient experience}

The major difference in Rheumatology training is that in Poland a typical out-patient clinic placement is only for 6 weeks whereas in the UK it is ongoing throughout the 5-year placement. In the UK, Rheumatology training is mainly out-patient based, where trainees have their own clinic lists throughout the years of training with supervision from their consultants. Usually, the trainee will carry out four clinic sessions a week with a mixture of both new and follow-up patients [5].
Table II. Rheumatology training - 2 year's duration. Table translated from CMPK website (Centre of Postgraduate Medical Education: http://www.cmkp.edu.pl/ksztalcenie-podyplomowe/studia-specjalizacyjne-lekarzy/ programy-specjalizacji-lekarskich/modulowe-programy-specjalizacji/)

\begin{tabular}{|c|c|c|}
\hline No. & Training & Duration in weeks \\
\hline 1 & Basic Rheumatology training & 62 \\
\hline 2 & Paediatric Rheumatology & 6 \\
\hline 3 & Imaging & 1 \\
\hline 4 & Orthopaedics & 1 \\
\hline 5 & Neurology & 1 \\
\hline 6 & Rehabilitation & 1 \\
\hline 7 & Out-patient rheumatology & 6 \\
\hline 8 & Dermatology & 1 \\
\hline 9 & Pain clinic & 1 \\
\hline 10 & $\begin{array}{c}\text { Placement directed by the } \\
\text { programme director }\end{array}$ & 4 \\
\hline 11 & Speciality courses & 3 weeks and 2 days \\
\hline 12 & Study leave & 1 week and 2 days \\
\hline 13 & Annual leave & 10 weeks and 2 days \\
\hline 14 & Bank Holidays/days off & 5 weeks and 1 day \\
\hline 15 & Total & 104 weeks and 2 days \\
\hline
\end{tabular}

In the UK, after each patient visit to the out-patient clinic, a doctor will dictate a short note with the diagnosis, clinical findings, plan and results of the investigations to the general practitioner, other parties/consultants and the patient. In Poland, this is not a common practice, as usually the doctor will record a short note in the case notes and/or in the computerised record. If necessary, a short letter can be written by a hospital doctor to the general practitioner.

Out-patient experience is vital in rheumatology; therefore consistent clinics through the years of training prepare trainees well and enable them to be able to deal with the majority of rheumatological presentations. The UK system is also more formalised, with the letters being dictated in the clinic and then typed and sent off to the relevant doctors/medical professionals and the patients.

\section{Training curriculum: competencies and assessments}

Throughout Rheumatology training in the UK, one must gain and demonstrate generic competencies in- 
cluding history taking and examination, as well as management of rheumatological conditions. Trainees are expected to be competent in intra-articular joint injections - trainees may frequently run an injection clinic. To progress through training, trainees must have a certain number of workplace-based assessments: case-based discussions, examination assessments and procedures signed off by the supervising consultant. In addition, one formal teaching session has to be assessed by a consultant and one audit a year is obligatory [2].

In both the Polish and UK curriculum, participation in research is encouraged. In the UK, if one wishes to obtain a PhD then it is best done during the training (one must go out of the programme to do so). In Poland, the PhD can be done at the same time as the training or after the training is completed. In the UK a trainee can also take time out of the programme to obtain an MD degree. In Poland after successfully finishing the medical degree one is awarded with an MD title.

In both Poland and the UK, Rheumatology trainees are encouraged to initially review all the consultations (referrals) on the wards or from other departments. Depending on their seniority and the departmental rules, the trainee may perform the consultations independently and then report to their consultant, or attend together with their senior colleague [6]. The consultant might then review the patient him/herself or may simply give advice.

In the UK each trainee has to complete an on-line portfolio (e-portfolio), where they are required to perform and record a certain number of workplace-based assessments that focus on different aspects of patient care. Some are based on core competencies such as history taking skills, clinical examination, leadership, management, safe prescribing, clinical governance, structure of the NHS, professionalism, quality care and patient safety, medical ethics and legal issues. That prepares trainees to be better all-rounded doctors who can apply learned skills in clinical practice [7]. In addition, trainees must collect a certain number of new competencies in procedures (e.g. different joint injections). Patient survey as well as multi-source feedback is also a requirement to progress through training. Patient survey is a patient's feedback on the doctors' attitude, communication skills, approach to the patient and general consultation skills. Multi-source feedback is a form that is sent to at least twelve different staff members that asks about doctors' communication skills, attitude to patients and staff members, reliability, team playing and leadership skills as well as professionalism in general. Each year, trainees must successfully go through an Annual Review of Competence Progression. A fail might mean an extension of training or other more severe consequences [2]. In Poland, the trainee must pass small assessment exams that are scored by the doctors' specialty trainer. These can be either written or oral.

As far as obligatory curriculum teaching is concerned, in the UK it is usually equally distributed throughout the years by attending regular days or half-days of regional teaching sessions. In Poland this is usually organised as a course that can vary in length and the trainees can choose the date most suitable for them.

\section{Conclusions}

In conclusion, the two training programmes are similar in length and in the competencies that must be achieved, although they do have significant differences in the way the training is structured. The UK-based system is more out-patient based, which can be advantageous, as after completion of training the doctor is more confident in treating common rheumatological problems and trained in time management skills that are vital in the clinic setting. Although somewhat burdensome and time-consuming, the recording and assessment of competencies in the UK appear more formalised, providing objective evidence that training requirements have been completed. Furthermore, trainee feedback from many different consultants rather than just one can be advantageous. On the other hand, having exposure to paediatric rheumatology and orthopaedics like one has in Polish-based training, despite a short placement time, is definitely beneficial for the trainee in gaining allround knowledge. In addition, as far as the general medical training is concerned, being exposed to the majority of medical specialties is also of benefit to the trainees, as opposed to having experience in only 6 or 8 of them as is the case in the UK. In conclusion, each system has its merits and can be further enhanced by observing how junior doctors are sub-specialty trained in different countries. In the same way, different countries can learn from each other's practices and improve their own medical training programmes. Perhaps exchange programmes that are a common practice in the medical schools could be implemented for those in training in order to unify and strengthen specialty training worldwide. One that would be equally popular amongst medical students and would benefit trainees is a research exchange programme in which trainees from another country could carry out a small research project or learn new skills, e.g. MSK ultrasound, in a different country. That would definitely broaden the trainees' horizons and also be beneficial for their patients' care in the future. Rheumatology specialists' education systems vary from country to country due to differences in the struc- 
ture of health care organizations as well as past historical addictions. Total unification of specialist education is probably not possible, but convergence of the specialization would be beneficial for scientific cooperation and improved patient treatment. The topic discussed in the article also may be a point of discussion in the EULAR forum.

The authors declare no conflict of interest.

\section{References}

1. Joint Royal Colleges of Physicians Training Board (JRCPTB). ST3 Recruitment. 21-1-2016.
2. Joint Royal Colleges of Physicians Training Board (JRCPTB). JRCPTB - ARCP. 2016.

3. Centrum Medyczne Ksztalcenia Podyplomowego (CMPK). Program specjalizacji z Reumatologii. 2016.

4. Centrum Medyczne Kształcenia Podyplomowego (CMPK). 2016.

5. Centrum Medyczne Kształcenia Podyplomowego (CMPK). Akredytacja 2014. Program specjalizacji z Reumatologii. 2016.

6. Foster HE, Everett S, Myers A. Rheumatology training in the UK: the trainees perspective. Rheumatology 2005; 44: 263264.

7. Lillicrap M, Otter S, Haq I. Rising to the challenge: rheumatology can lead in multi-professional education and training globally in the 21st century. Rheumatology (Oxford) 2016; 55: 1932-1937. 